\title{
Notes on the vocalizations of Paradise Crow (Lycocorax pyrrhopterus)
}

\section{Peter Boesman}

In the following we briefly analyze and compare voice of the three races of Paradise Crow (Lycocorax pyrrhopterus). We also try to quantify the extent of any vocal differences using the criteria proposed by Tobias et al. (2010), as a support for taxonomic review.

We have made use of sound recordings available on-line from Xeno Canto (XC) and Macaulay Library (ML).

An overview of the different vocalizations per race which we found in the available on-line recordings:

\section{nominate}

An explosive guttural "keh!", single or doubled/tripled
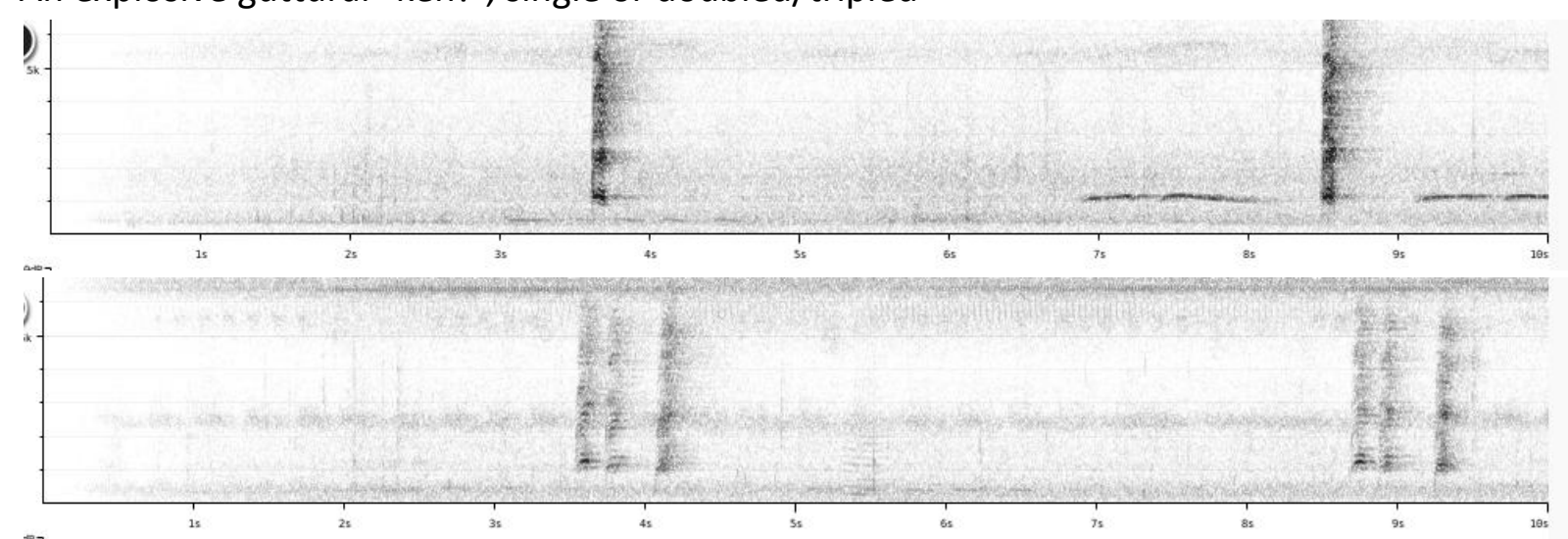

A drawn-out grating note

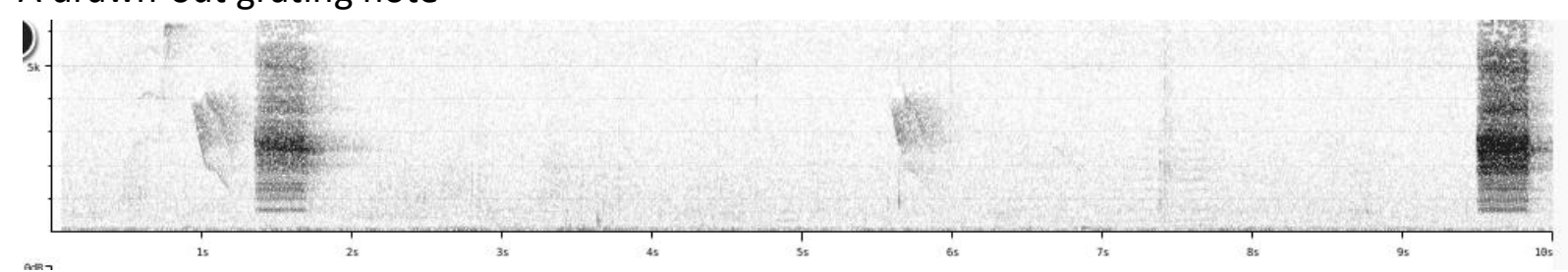

\section{Race morotensis}

An explosive guttural "keh!", single or doubled/tripled

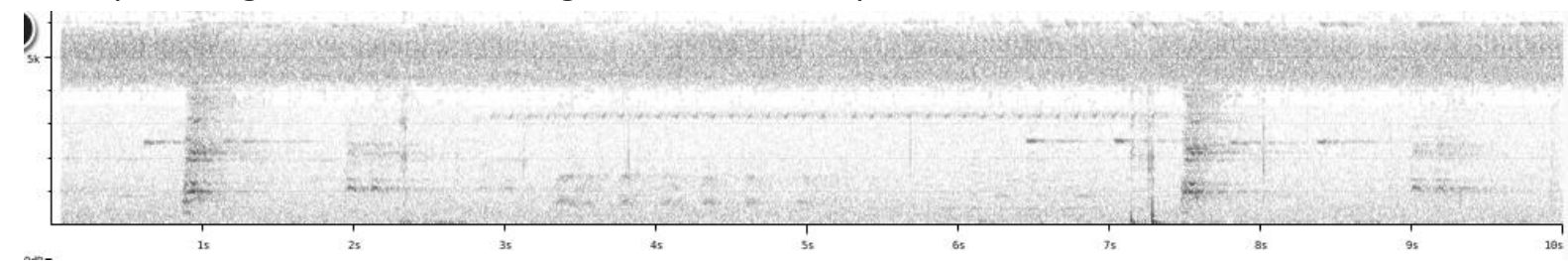




\section{HANDBOOK OF THE \\ BIRDSPFGTE WORLD}

\section{ORNITHOLOGICAL NOTES}

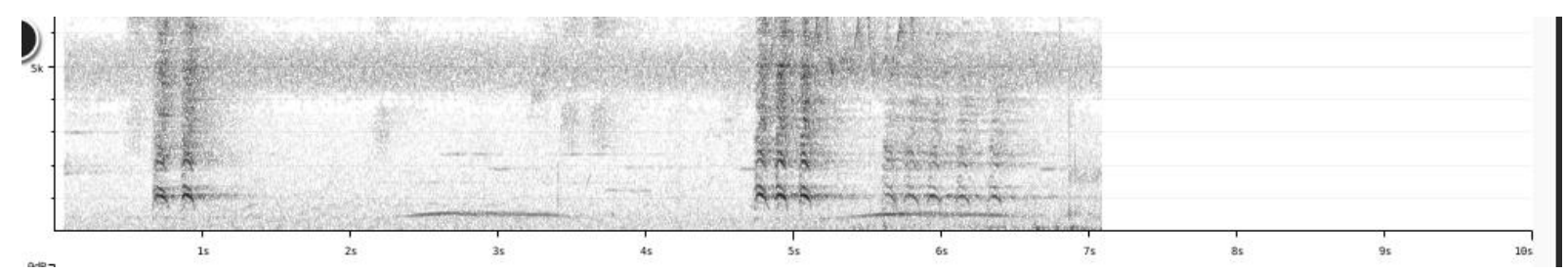

A nasal plaintive "kyeh"

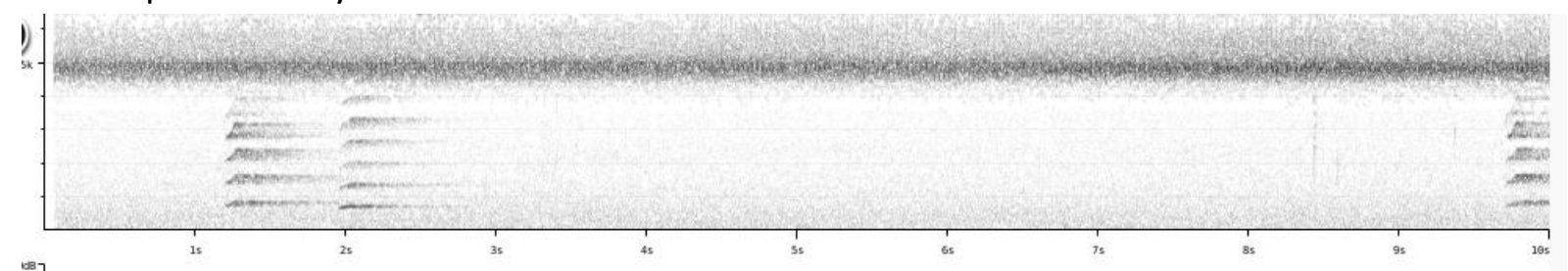

Presumed song, a low-pitched popping whistle 'whup!'

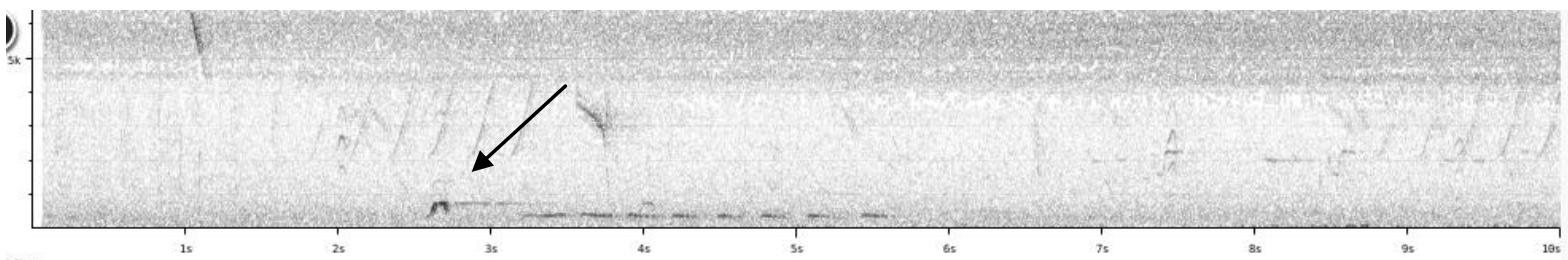

\section{$\underline{\text { Race obiensis }}$}

A clicking or clapping like note (doubled)

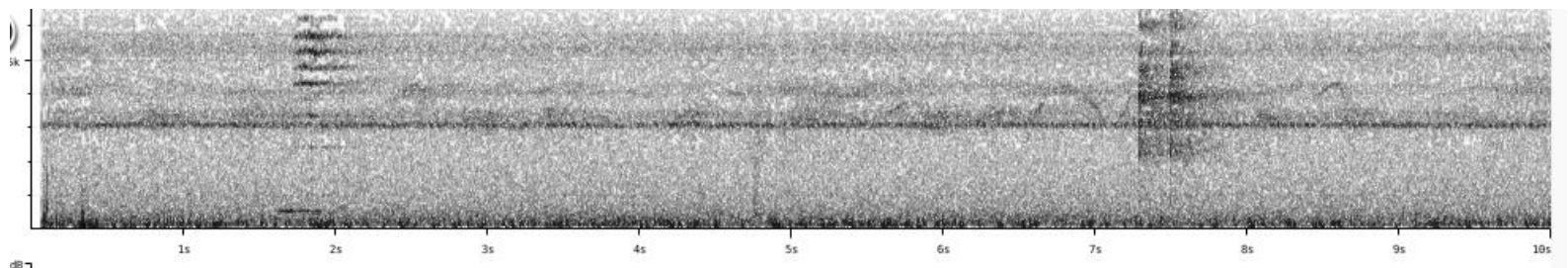

An electric single note "kek"

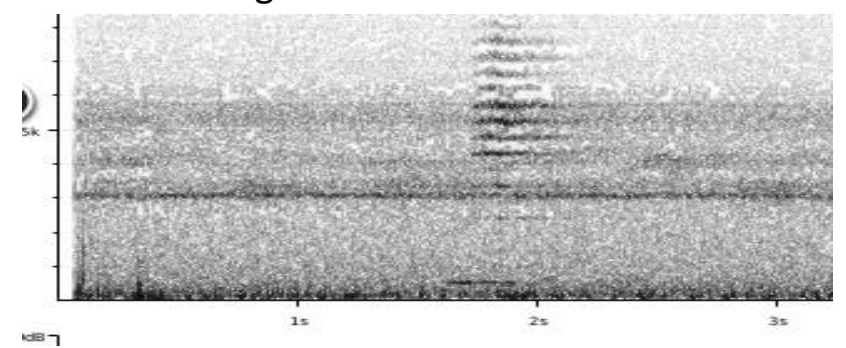

An explosive guttural "weh!", single or doubled/tripled

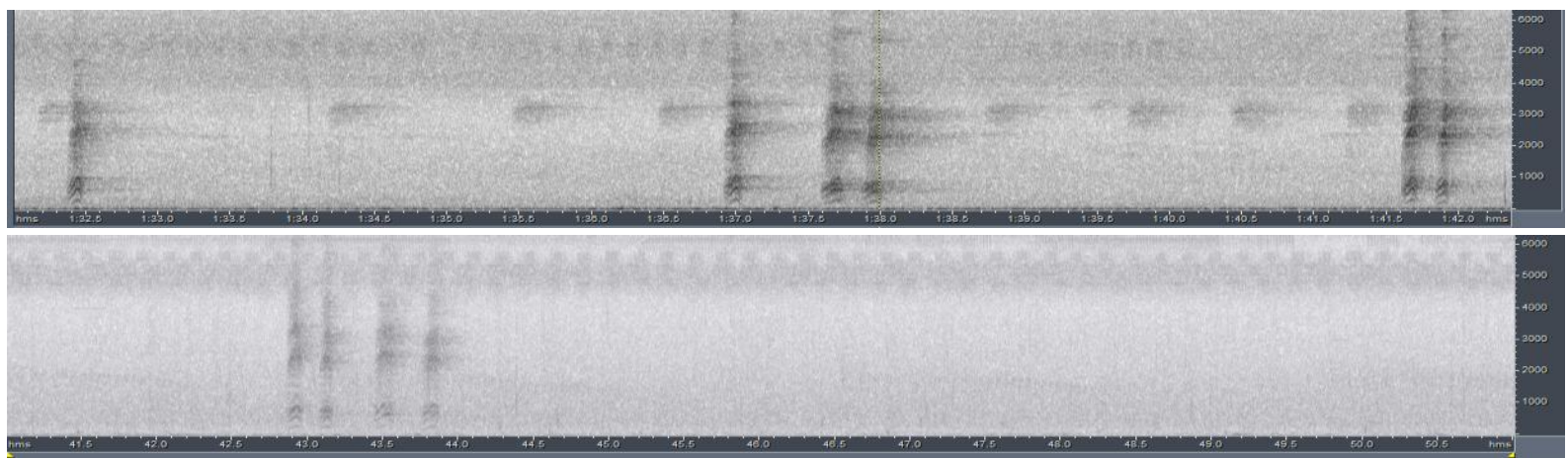



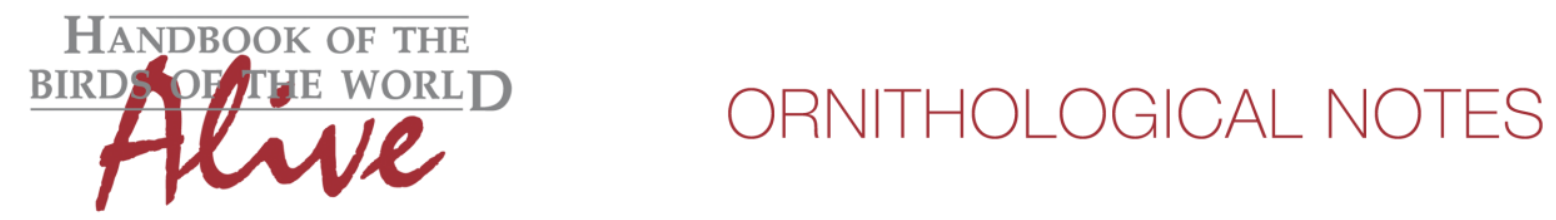

Presumed song, a hollow mournful monosyllabic or bisyllabic whistle "whoo" or "whu-oo" (other frequency scale !)

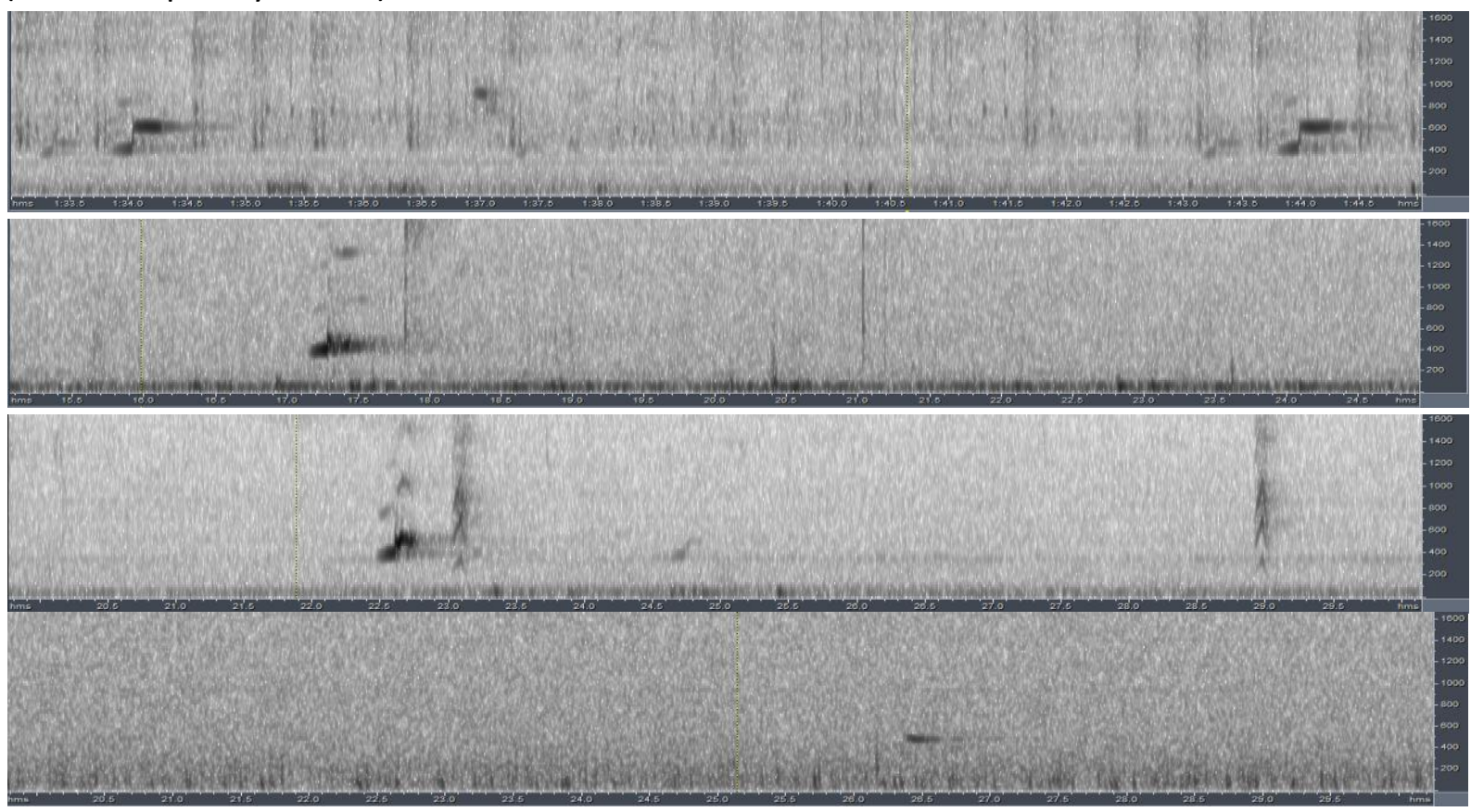

There are apparently no recordings available of the whistled song for nominate, thus not allowing a comparison of this vocalization.

There are nevertheless clear indications that the vocabulary of obiensis is different, with also the guttural call different from the two other races (different distribution of the frequency bands).

The song whistle of obiensis is very different from morotensis, the former being (often) clearly bisyllabic and less emphatic. We have only one example of the latter however.

It is thus too speculative to score the vocal differences, but there are clear indications that the homologous vocalizations are different.

This note was finalized on 2nd February 2016, using sound recordings available on-line at that moment. We would like to thank in particular the sound recordists who placed their recordings for this species on XC and ML: Patrik Åberg, K. Gareth, Frank Lambert, John Mittermeier, Mike Nelson and Mark Thibault. 



\section{References}

Tobias, J.A., Seddon, N., Spottiswoode, C.N., Pilgrim, J.D., Fishpool, L.D.C. \& Collar, N.J. (2010). Quantitative criteria for species delimitation. Ibis 152(4): 724-746.

\section{Recommended citation}

Boesman, P. (2016). Notes on the vocalizations of Paradise Crow (Lycocorax pyrrhopterus). HBW Alive Ornithological Note 212. In: Handbook of the Birds of the World Alive. Lynx Edicions, Barcelona. (retrieved from http://www.hbw.com/node/932162 on 6 September 2016). 